\title{
Clinical Significance of Blastocystis Sp. among Children with Leukemia
}

Zainab Khalid khalil *

\section{ABSTRACT}

Background: Blastocystis spp. distributes world widely and the genus Blastocystis include many subtypes that are isolated from human intestinal tract. It is considered the most common parasite detected in human being.

Objectives: To evaluate the incidence of Blastocystis spp. among leukemic children, to find out its association with the presence of symptoms (diarrhea and abdominal pain), and to assess the efficacy of different staining methods in detection of Blastocystis spp.

Type of the study: cross-sectional study.

Method: 103 children were enrolled in this study, 53 leukemic patients and 50 healthy controls. The study was performed during the period between January and June 2014, in Oncology department of Ibn Al-Atheer teaching hospital in Mosul city. Three consecutive samples were taken from each child and a thorough history was taken from them. The samples then treated with 3 stains, iodine, iron hematoxylin, and trichrome.The data was analyzed using minitab version 17, Fischer's exact test, Twoproportions test, and Correlation test. The results were considered statistically significant with $\mathrm{P}$-value $<0.05$.

Results: Blastocystis spp. was detected in $18.87 \%$ of leukemic children and in $10 \%$ of healthy group. All specimens were stained by iodine, iron hematoxylin, and trichrome stains. Infection rates among patients were $(9.4 \%$,
$11.3 \%$, and $18.87 \%$ respectively) while among healthy children they were $(4 \%, 6 \%$, and $10 \%$ respectively). However, these differences were statistically nonsignificant. A higher infection rate was detected in the preschool children (33.3\%) than school age group (6.9\%). Furthermore, there was a significant association between Blastocystisspp. infection and intestinal symptoms (abdominal pain and diarrhea).

Conclusion: Our study reveals a higher rate of infection with Blastocystis spp. among leukemic children than normal controls and a significant association was seen between incidence of Blastocystisspp. infection and symptomatic children. Those results draw attention for the significance of Blastocystis spp. infection in immunosuppressed patients and lighten the way for further studies on its pathogenicity and diagnostic methods.

Key words:Blastocystis, Leukemia, Immunosuppression

\section{Al-Kindy College Medical Journal 2017: Vol. 13 No.2} Page: 101-105

\author{
* M.B.Ch.B, Ms.C in microbiology \\ Received $30^{\text {th }}$ March 2017, accepted in final $19^{\text {th }}$ June \\ 2017 \\ Corresponding to : zainab Khalid khalil, email: : \\ D zainab009@yahoo.com, Mobil: 07719274048
}

Lastocystisspp. are unicellular, anaerobic enteric parasites that was considered as a harmless yeast in the past (1) .It is distributed worldwide and found in almost all species of animals .It increases especially in developing countries in the tropics and sub tropics (2). Blastocystis spp. is one of the most common intestinal protozoa found in human intestinal tract (3).Nine subtypes (genotypes) of Blastocystis are described on the basis of small subunit ribosomal RNA gene analysis (4). As well, isolates from humans and animals can be divided into 12 species, several of which are found in humans and no subtype exclusive to them $(5,6)$.Consequently, human isolate should be referred as Blastocystis spp. instead of Blastocystishominis.All Blascytostis spp. that were isolated from humans and animalshave been reported to be morphologically similar and cannot be differentiated microscopically (7).the morphological stages preset in stool sample include vacuolar, granular, and amoeboid. The vacuolated form is most commonly found in feces and responcible for transmitting infection by fecal-oral route (8). The pathogenicity of Blastocystis spp. is still an issue of controversy. Initially, it was believed to be a commensal protozoan, but recent studies support its pathogenisity in certain situations (9). The incidence of Blastocystis spp. increases in malignancy causing symptomatic or a symptomatic infections. The clinical manifestations among symptomatic individuals include diarrhea, vomiting, abdominal pain, flatulence (10). The disease progresses rapidly in patients with leukemia in particular $(11,12)$.Leukemia is the most prevalent malignancy in children below 15 years. A large number of leukemic children become victims of infections that considered a lethal cause in leukemia (13). Diagnosis of Blastocystis spp. is based on microscopic detection using direct wet mount preparation method with lugol's iodine or trichrome stain which is more sensitive for identification of the protozoa (14). Monotherapy with metronidazole is the most commonly recommended drug with eradication rates vary from $0-100 \%$ (15).Studying the prevalence of Blastocystis spp. in patients with leukemia will help inassessment of its pathogenisity and correlation with diarrhea and abdominal pain among those immunosuppressed children.

Methods: This study was conducted during January to June 2014 on two groups; fifty three children (28 male, 25 female) with leukemia attending Oncology 
department of Ibn Al Atheer teaching hospital in Mousl City, and fifty apparently healthy children ( 25 male, 25 female)included patient relatives as a control group.All children were between ages of (1.5-12 years) and the two groups were matched by age and sex to each other. A special data was provided for each child in the study included (Age, Sex, Residence, presence or absence of diarrhea\& abdominal pain).

Stool sample collection: Three consecutive stool specimens were collected from each child and stored in wide mouth tightly closed containers. These containers were labeled with the child name,age, date of collection .Each stool sample was stored in $10 \%$ formalin solution. The samples were centrifuged by $\mathrm{ZnSO} 4$ and formalether (ethyl acetate) concentration technique. Sediments were examined by Wet mount with Lugol's iodine, Iron hematoxylin, and trichrome stain (16) (17).

Statistical analysis: Statistical interpretation of data was performed by using the computerized software program minitab version 17. Fischer's exact test and Twoproportions test were used to compare between the variables in the study, while Correlation test was used to detect a possible association between Blastocystisspp. infection and symptoms (diarrhea \& abdominal pain). All $P$ values $>0.05$ were considered statistically insignificant.

Results: Blastocystis spp. was found in 10 (18.87\%) of the 53 leukemic children and in $5(10 \%)$ of the 50 healthy control group Fig.1. Table 1 shows the distribution of Blastocystis spp. in the study and control groups according to gender and area of residency. The infection rate was higher among male than female in both patients (25\%, $21 \%)$ and controls $(12 \%, 8 \%$ respectively). Also it was higher in rural than urban among leukemic children $(20 \%, 17.4 \%)$ and healthy group $(15.4 \%, 4.2 \%)$ respectively. Although, infection rates were higher among patients than controls, these differences were statistically insignificant. Fig. 2 All of the collected samples were stained by 3 types of stains iodine, iron hematoxylin and trichrome. The infection rates were $(9.4 \%, 11.3 \%$, and $18.87 \%$ respectively) in the patients group and ( $4 \%, 6 \%$, and $10 \%$ respectively) in the control group. The highest infection rates were recorded when the samples stained with trichrome and higher infection rates were seen among the patients than the controls but the difference was nonsignificant and $p$ value $>0.05$. In table 2 the leukemic children were divided according to the age in to two groups. The first group included children< 6 years (preschool) who showed an infection rate of $(33.3 \%)$, while the second group included those $\geq$ 6 years (school age) with an infection rate of $(6.9 \%)$. This difference was statistically significant with $p$ value 0.004.Again the patients were divided into two groups (symptomatic \& a symptomatic) according to the presence and absence of diarrhea and abdominal painin order to study the correlation between Blastocystisspp. infection and clinical symptoms. $50 \%$ of the $1^{\text {st }}$ group was positive for Blastocystis spp. while only $2.85 \%$ of the second groupwas positive.
The difference was statistically significant and adirect relationship was found between theappearance of symptoms (diarrhea \& abdominal pain) and Blastocystisspp. infection Fig.3.

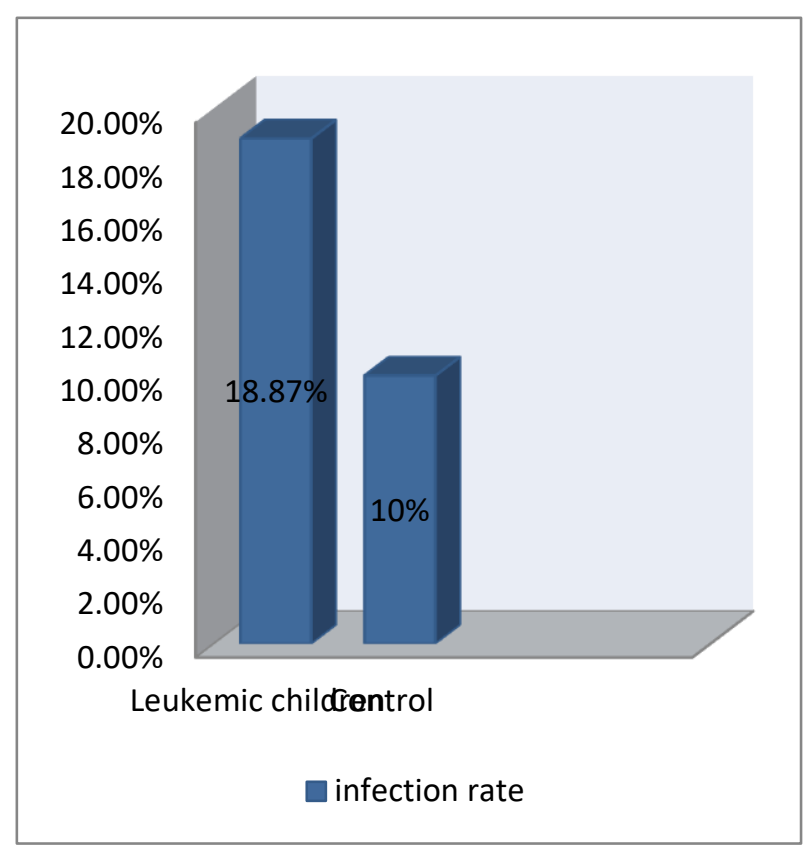

Fig.1: Difference between infection rate with Blastocystis spp. in leukemic children and control

Table 1: The rate of infection with Blastocystis spp. according to the gender and place of studied children

\begin{tabular}{|c|c|c|c|c|c|c|c|}
\hline \multirow{2}{*}{\multicolumn{2}{|c|}{$\begin{array}{r}\text { Characterist } \\
\text { ic }\end{array}$}} & \multicolumn{3}{|c|}{ patients } & \multicolumn{3}{|c|}{ control } \\
\hline & & $\begin{array}{l}\text { Exa } \\
\text { mine }\end{array}$ & $+v e$ & $-v e$ & $\begin{array}{l}\text { Examine } \\
\text { d }\end{array}$ & $+v e$ & -ve \\
\hline \multirow{4}{*}{$\begin{array}{c}\text { Gen } \\
\text { der }\end{array}$} & Male & 28 & 7 & 21 & 25 & 3 & 22 \\
\hline & & & $25 \%$ & $75 \%$ & & $12 \%$ & $\begin{array}{l}88 \\
\% \\
\end{array}$ \\
\hline & Fem & 25 & 3 & 22 & 25 & 2 & 23 \\
\hline & & & $12 \%$ & $88 \%$ & & $8 \%$ & $\begin{array}{r}92 \\
\%\end{array}$ \\
\hline \multirow{4}{*}{$\begin{array}{r}\text { Plac } \\
\mathrm{e}\end{array}$} & Urba & 23 & 4 & 19 & 24 & 1 & 23 \\
\hline & & & $\begin{array}{r}17.4 \\
\% \\
\end{array}$ & $\begin{array}{r}82.6 \\
\% \\
\end{array}$ & & $\begin{array}{r}4.2 \\
\% \\
\end{array}$ & $\begin{array}{l}95 . \\
8 \% \\
\end{array}$ \\
\hline & Rura & 30 & 6 & 24 & 26 & 4 & 22 \\
\hline & & & $20 \%$ & $80 \%$ & & $\begin{array}{r}15.4 \\
\%\end{array}$ & $\begin{array}{l}84 . \\
6 \%\end{array}$ \\
\hline
\end{tabular}



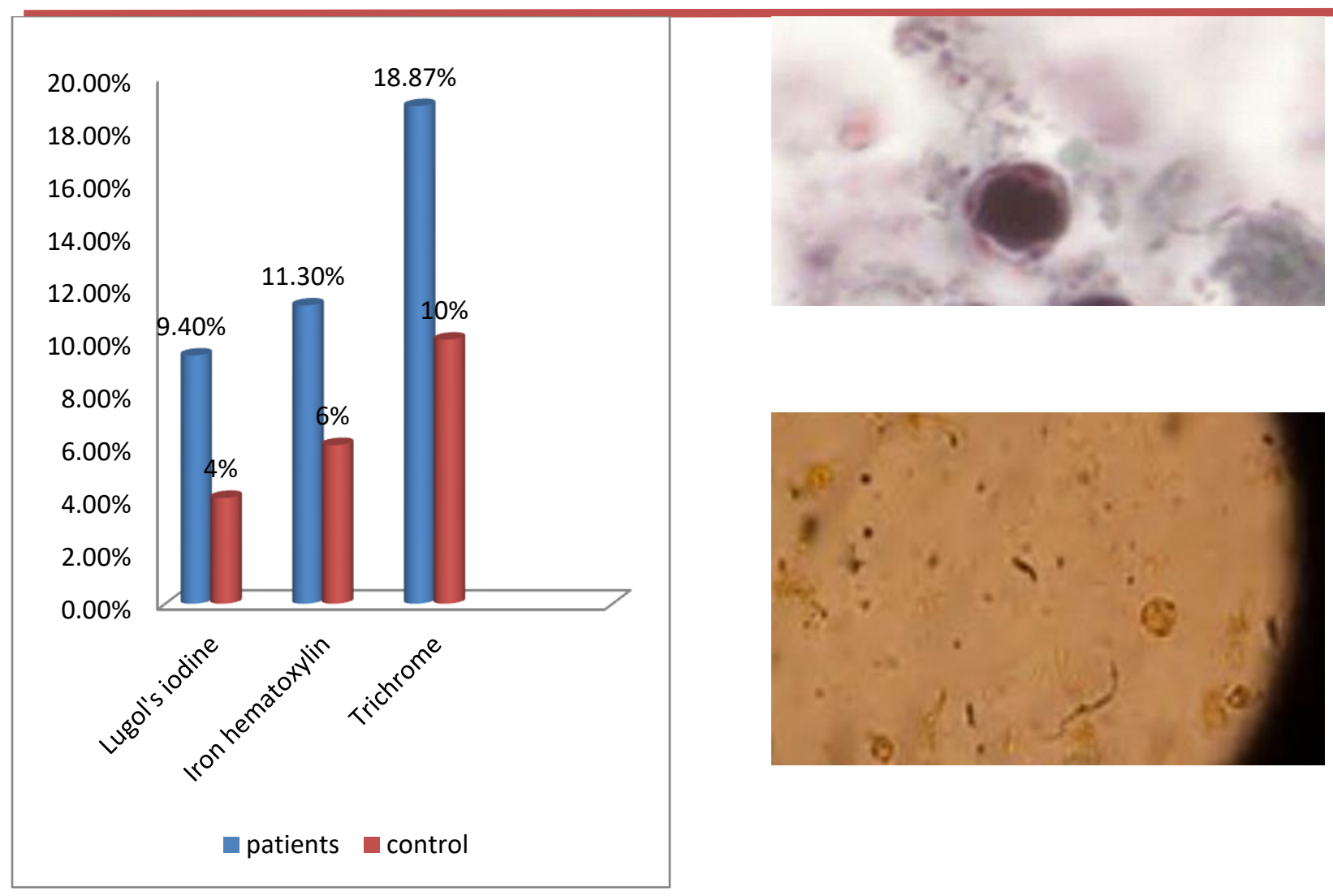

Fig.2: Comparison between efficacy of different staining methods for diagnosis of Blastocystis spp. in leukemic children
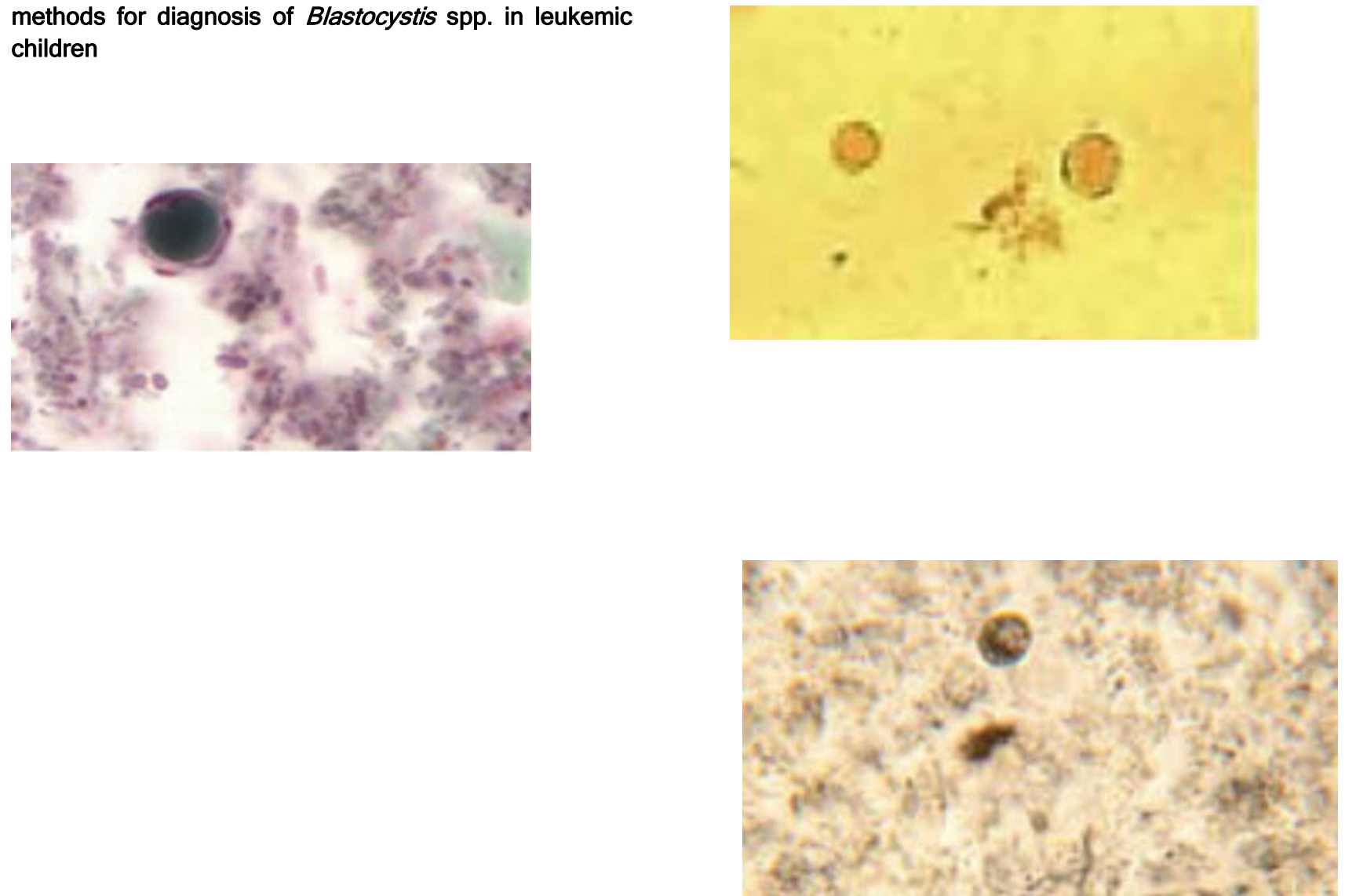
Blastocystis spp. cyst stained by Trichrome stain (large central vacuole stained gray-green color and the peripheral nuclei stained red-purple color)

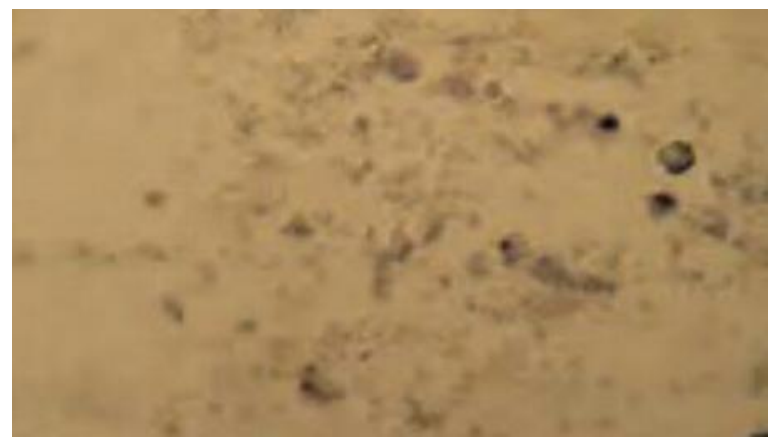

Blastocystis spp. cyst stained by Lugol's iodine stain (large central vacuole stained yellow-brown color and the peripheral nuclei stained dark brown-black color) Blastocystis spp. cyst stained by Iron hematoxylin stain (large central vacuole stained gray color and the peripheral nuclei stained black color)

Table 2: The relationship between age group of leukemic children and Blastocystisinfection

\begin{tabular}{|c|c|c|c|}
\hline Age group & $\begin{array}{c}\text { Examined } \\
\text { no. }\end{array}$ & Positive & Negative \\
\hline $\begin{array}{c}\text { preschool } \\
\text { age } \\
(<6 \text { years })\end{array}$ & 24 & 8 & 16 \\
\hline $\begin{array}{c}\text { School age } \\
(\geq 6 \text { years })\end{array}$ & 29 & $33.3 \%$ & $66.67 \%$ \\
\hline Total & 53 & 10 & $43 \%$ \\
\hline
\end{tabular}

Figure-3- Association of Blastocystis spp. infection with diarrhea in patients group.

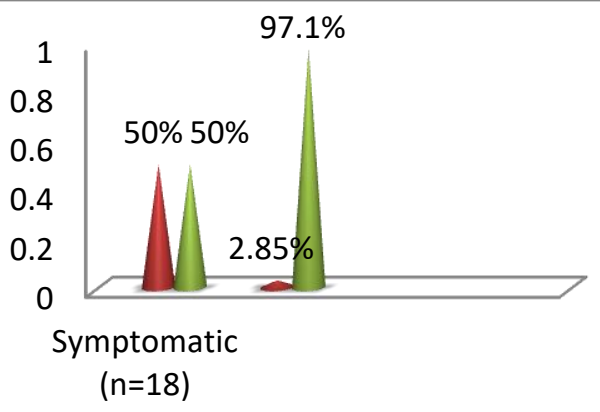

infected non infected
Discussion:Blastocystis spp. is a ubiquitous parasite with a wide world distribution. It's prevalence differ from country to country and in variable communities within the same country $(18,19)$. However, the truth about it's being a commensal or a pathogenic parasite in certain conditions is still a questionable matter (21).many reports about the incidence of Blastocystis spp. in immunocompromised individuals are available (20). In our study, $18,87 \%$ of the patients were positive for Blastocystis spp. compared to $10 \%$ of the controls and the difference was statistically insignificant. A similar study done by Aksoyet al. who found no statistically significant difference in the incidence of Blastocystis spp. in patients with malignant neoplasms (26\%) compared to a healthy group which was $4 \%$ (16). Essa et al. results were against that and he attributed his findings to the lower exposure of leukemic children to pathogens due to lower activity and more care by their food and hygiene (13). Furthermore, there was no significant difference in the incidence of Blastocystis spp. among male and female groups and among rural and urban groups is in agreement with many similar result studies $(3,13,22)$. In the present study, we use different staining methods including iodine, iron hematoxylin, and trichrome stains that shows an infection rates of $(9.4 \%, 11.3 \%$, and $18.87 \%$ respectively) in immunosuppressed group while ( $4 \%, 6 \%$, and $10 \%$ respectively ) in the healthy controls. We noticed that trichrome staining method detected more positive cases than the other two methods and this is in agreement with many other studies that showed trichrome as the most sensitive stain for diagnosis of Blastocystis spp. $(23,24)$. We noticed that the Blastocystisspp. infection rates were higher in the preschool than the school age group. That may be attributed to the higher activity of children under 6 years old and less awareness of hygienic aspects (16). In the other hand, we found that infection by Blastocystis spp. was significantly correlated with the presence of diarrhea and abdominal pain, and that was similar to El Shazlyet al and kaya et al studies $(25,26)$. Other authors suggested that such symptomatic individuals had no correlation with being positive for Blastocystis spp. (27, 28). This disparity is controversy, but it may be attributed to the wide variety of the isolated subtypes and host defense factors like age and immune status.

Conclusions: Our findings reported that Blastocystisspp. infection was seen more frequently among leukemic children and there was a significant association with the presence of diarrhea and abdominal pain. Those findings are expected to produce anawareness about the right diagnostic method for Blastocystis spp. and open doors for further studies on its prevalence and pathogenicity. 


\section{References}

1. Robyn N, Helle BO and Rebecca T. Clinical pilot study: efficacy of triple antibiotic therapy in Blastocystis positive irritable bowel syndrome patients. Gut Pathog J 2014; 6:34-1.

2. Stark D, Barratt JLN, Van Hal S, et al. Clinical significance of enteric protozoa in the immunosuppressed human population. Clin. Microbiol. Rev.2009; 22:634-650.

3. Awatif MA, Init I, Hesham MA, et al. Prevalence, predictors and clinical significance of Blastocystissp. in Sebha, Libya. Parasites \& Vectors 2013; 6:86-1.

4. Stensvold CR, Arendrup MC, Jespersgaard C, et al. Detecting Blastocystisusing parasitologic and DNAbased methods: a comparative study. Diagn. Microbiol. Infect Dis 2007; 59:303-310.

5. Parkar U, Traub RJ, Kumar S, et al. Direct characterization of Blastocystis from faeces by PCR and evidence of zoonotic potential. Parasitology 2007; 134:359-367.

6. Christina MC, Julie V, Louis MW, et al. Blastocystis: to treat or not to treat. CID 2012; 54:105-110.

7. Kevin SWT. New insights on classification, identification, and clinical relevance of Blastocystisspp. Clin. Microbiol. Rev.2008; 21:639665.

8. Javed $\mathrm{Y}$, Wasim J, Nadim J, et al. Irritable bowel syndrome: in search of an etiology: Role of Blastocystishominis.Am. J. Trop. Med. Hyg.2004; 70:383-385.

9. Jean FR, Samir MK, Mohammed S, et al. Effect of nitazoxanide in persistent diarrhea and enteritis associated with Blastocystishominis.Clin. Gastroenterol\&Pathol 2005; 3:987-991.

10. Abdulsalam AM, Ithoi I, Al-MekhlafiHM, et al. Drinking water is a significant predictor of Blastocystisinfection among rural Malaysian primary schoolchildren. Parasitol2012; 139:10141020.

11. Umit A, Ayse E, Ciler A, et al. Intestinal parasites in children with neoplasms. Turk J Pediatr 2003; 45:129-132.

12. Rose AK, Dina LMF, Leticia N, et al. Blastocystissp. and other intestinal parates inhemodialysis patients. BJID 2008; 12(4): 338-341.

13. Safaa ME, Hala $S A$, Sanaa $A E$, et al. Blastocystishominisamong immunocompromised and immunocompetent children in Alexandria, Egypt. IMed Pub J 2016; 4(2):92.

14. Selcuk K, Emel SC, Buket CA, et al. Pathogenicity of Blastocystishominis, A clinical reevaluation. Turk ParasitolDerg2007; 31 (3): 184-187.
15. Stensvold CR, Smith HV, Nagel R, et al. Eradication of Blastocystiscarriage with antimicrobials: reality or delusion?. J ClinGastroenterol2009; 44(2): 85-90.

16. Aksoy U, Akisu C, Bayram S, et al. Demographic status and prevalence of intestinal parasitic infections in schoolchildren in Izmir, Turkey. Turk. J. Pediatr.2007; 49:278-282.

17. Noor A, San YM, Gan CC, et al. Prevalence of intestinal protozoa in an aborigine community in Pahang, Malaysia. Trop. Biomed.2007; 24:55-62.

18. Baldo ET, Belizario VY, De Leon WU, et al Infection status of intestinal parasites in children living in residential institution in Metro Manila, the Philippines. Korean J. Parasitol. 2004; 42:67-70.

19. Florez AC, Garcia DA, Moncada L, et al. Prevalence of microsporidia and other intestinal parasites in patients with HIV infection. Bogota Boimedica.2003; 23:274-282.

20. Wumba R, Enache-Angoulvant A, Develoux $M$, et al. prevalence of opportunistic digestive parasitic infections in Kinshasa, Democratic Republic of Congo. Results of a preliminary study in 50 AIDS patients. Med Trop. 2007; 67(2): 145-153.

21. Tekola E, Gemechu T and Beyene P. Significance of Blastocystishominisin patients referred for bacteriological stool culture at EHNRI. Ethiop. J. Health Dev. 2007; 21(1): 61-67.

22. Hegazy MM, Maklouf LM, El Hamshary EM, et al. Protein profile and morphometry of cultured human Blastocystishominisfrom children with gastroenteritis and healthy ones. J Egypt SocParasitol. 2008; 38: 453-464.

23. Ozcakir O, Gureser S, Erguven S, et al characteristics of Blastocystishominisinfection in Turkish university hospital. Turk ParazitolDerg. 2007; 31: 277-282.

24. Forbes BA, Sahm DF and Weissfeld AS. Laboratory methods for diagnosis of parasitic infections in: Baily Scott's. Diag. Microbil. 2002; 11:606.

25. El-Shazly AM, Abdel-Magied AA, El-Beshbishi, et al. Blastocystishominisamong symptomatic and asymptomatic individuals in Talkha Center, Dakahilia Governorate, Egypt. J. Egypt. Soc. Parasitol. 2005; 653-666.

26. Kaya S, Cetin ES, Aridogan BC, et al. Pathogenicity of Blastocystishominis, a clinical reevaluation. Turk. Parazitol. Derg. 2007; 31: 184-187.

27. Leder K, Hellared ME, Sinclair, et al. No correlation between clinical symptoms and Blastocystishominisin immunocompetent individual. J GastroenterolHepatol. 2005; 20(9): 1390-1394.

28. Kuo HY, Chiang DH, Wang CC, et al. Clinical significance of Blastocystishominis: experience from a medical center in northern Taiwan. J Microbiollmmunol Infect. 2008; 41(3):222-228 